\title{
Frege on Vagueness and Ordinary Language
}

\author{
Stephen Puryear
}

\begin{abstract}
Frege supposedly believed that vague predicates have no Bedeutung. But given other things he evidently believes, such a position would seem to commit him to a suspect nihilism according to which assertoric sentences containing vague predicates are neither true nor false. I argue that we have good reason to resist ascribing to Frege the view that vague predicates have no Bedeutung and thus good reason to resist seeing him as committed to the suspect nihilism.
\end{abstract}

In some comments on his classic essay Über Sinn und Bedeutung, Frege affirms what has come to be known as his sharpness requirement on concepts: "It must be determinate for every object whether it falls under a concept or not; a concept word that does not meet this requirement on its Bedeutung is bedeutungslos" (NS 1:133/PW 122). ${ }^{1}$ This text and others like it have given rise to something of a scholarly consensus according to which Frege endorses what I will call SHARPNESS:

(SHARPNESS) Vague or otherwise incompletely defined predicates have no Bedeutung. ${ }^{2}$

\footnotetext{
${ }^{1}$ Editions of Frege's works are cited using the following abbreviations: B: The Frege Reader, ed. M. Beaney (Boston: Blackwell, 1997); BS: Conceptual Notation, ed. T. W. Bynum (Oxford: Oxford University Press, 1972), cited by section number; CP: Collected Papers on Mathematics, Logic, and Philosophy, ed. B. McGuinness (New York: B. Blackwell, 1984); FA: The Foundations of Arithmetic (Evanston: Northwestern University, 1980); GG: Grundgesetze der Arithmetik, vol. 2, cited by section number; KS: Kleine Schriften, ed. I. Angelelli (Hildesheim: Georg Olms, 1967); NS: Nachgelassene Schriften, ed. H. Hermes, F. Kambartel, and F. Kaulbach (Hamburg: Felix Meiner, 1969), cited by volume and page number; PMC: Philosophical and Mathematical Correspondence (Chicago: University of Chicago, 1980); PW: Posthumous Writings, trans. P. Long and R. White (Chicago: University of Chicago, 1979).

${ }^{2} \mathrm{I}$ follow contemporary usage in calling vague only those predicates lacking well-
} 


\section{FREGE ON VAGUENESS AND ORDINARY LANGUAGE}

As several commentators have noticed, however, this rather extreme stance on vagueness appears to make trouble for Frege. ${ }^{3}$ Among the core doctrines of his philosophy of language are what I will call TRUTH-VALUE and COMPOSITION:

(TRUTH-VALUE) The Bedeutung of an assertoric sentence is its truthvalue.

(COMPOSITION) A sentence can have a Bedeutung only if the proper names and predicates that compose it each have a Bedeutung.

In conjunction with these doctrines, SHARPNESS entails that any assertoric sentence containing a vague or otherwise incompletely defined predicate must also lack a Bedeutung, that is, a truth-value. Yet it would appear that such sentences pervade ordinary speech. That is, it would appear that UBIQUITY is true:

(UBIQUITY) Most if not all ordinary language assertoric sentences employ vague or otherwise incompletely defined predicates.

By virtue of endorsing SHARPNESS, TRUTH-VALUE, and COMPOSITION, then, Frege appears to have committed himself to an extreme form of nihilism about vagueness according to which most if not all ordinary language assertions are neither true nor false.

This sort of nihilism about vagueness is surely not incoherent, but I suspect most philosophers would agree with Williamson that it must be regarded as a position of last resort $(1994,165)$. Kemp even suggests that Frege's commitment to such an approach is "ruinous" to his overall enterprise $(1996,169)$. And for good reason. If Fred is a borderline case of a bald man, then it stands to reason that 'Fred is bald' is neither true nor false. But if Fred is clearly bald or has a full head of hair, then it seems that 'Fred is bald' ought to have a truth-value despite the vagueness of the predicate 'bald'. Likewise, nothing could be more obvious than that statements such as 'Some people are bald', 'No electron is a heap', and 'All heaps of sand are heaps' have a truth-value. The conclusion that these statements actually

defined extensions (e.g., 'bald'). By "otherwise incompletely defined predicates," I mean non-vague expressions not defined for all objects (e.g., 'prime'). On Frege's tendency to lump these two cases together, see Dummett 1974, 646-48.

${ }^{3}$ See Rein 1985, 523; Weiner 1990; Burge 1991; Kemp 1996. 


\section{FREGE ON VAGUENESS AND ORDINARY LANGUAGE}

have no truth-value is therefore a rather bitter pill to swallow. Most of us would sooner reject a core Fregean doctrine such as TRUTH-VALUE or COMPOSITION than accept that such sentences are neither true nor false. Frege thus has a problem. Some of his core doctrines commit him to a conclusion that seems more implausible than the doctrines themselves.

In this essay, I want to explore our prospects for reading Frege in a way that avoids seeing him as committed to this extreme nihilism about vagueness. Unfortunately my task is made more difficult by the fact that the texts leave little room for the interpreter to wiggle. One option we can rule out right away is that of challenging Frege's commitment to TRUTH-VALUE and COMPOSITION. He affirms both doctrines repeatedly and unequivocally in his writings; there can be no reasonable question about his acceptance of them. ${ }^{4}$ As for SHARPNESS, this doctrine also seems to be well-grounded in the texts, and it has been ascribed to Frege by an impressive array of scholars. ${ }^{5}$ Burge, in particular, goes so far as to say that Frege's affirmations of this thesis are "frequent, straightforward and explicit" and that his acceptance of it cannot seriously be questioned $(1991,32,33,37)$. It would therefore seem that the only thing standing between Frege and the suspect nihilism is UBIQUITY, the thesis that vague or otherwise incompletely defined predicates are everywhere present in ordinary language. This thesis seems eminently plausible, but could it be that Frege did not believe it?

In what follows, I begin by considering Frege's attitude toward UBIQUITY. In Section 1, I examine some texts in which he seems to imply that concept-words that appear to us to be unsharp because of our inadequate grasp of their senses may actually manage to denote sharp concepts after all. Such texts might be taken as evidence that Frege meant to reject UBIQUITY; however, I argue that the preponderance of the evidence strongly points to his acceptance of UBIQUITY. In the remainder of the paper, I reconsider the evidence for ascribing SHARPNESS to Frege. In Section 2, I argue that the texts usually offered in support of this ascription are far from

\footnotetext{
${ }^{4}$ On COMPOSITION, see The Argument for my Stricter Canons of Definition, NS 1:168/PW 155; Introduction to Logic, NS 1:209-211/PW 192-194/B 294-296; Logic in Mathematics, NS 1:262/PW 243; On Sense and Bedeutung, KS 148-149/CP 162-163/B 157. On TRUTH-VALUE, see Comments on Sense and Bedeutung, NS 1:133/PW 122; Logic in Mathematics, NS 1:262/PW 243; Function and Concept, KS 131-134/CP 144-147/B 137-140; Frege to Husserl, 24 May 1891, NS 2:96/B 149; On Sense and Bedeutung, KS 148-151/CP 162-165/B 156-159; Frege to Russell, 28 December 1902, NS 2:234-235/B 255-56; Introduction to Logic, NS 1:210212/PW 194-195/B 296-98; Notes for Ludwig Darmstaedter, NS 1:276/PW 255/B 365.

${ }^{5}$ See, e.g., Dummett 1974, 169-70, 645-46; Dummett 1981, 34; Baker \& Hacker 1984, 253, 292; van Heijenoort 1986, 39; Weiner 1990, 107-8, 127-28; Burge 1991, 32-37; Williamson 1994, 41-46; Kemp 1996, 172.
} 


\section{FREGE ON VAGUENESS AND ORDINARY LANGUAGE}

conclusive and actually provide little evidence for the traditional reading. Then, in Section 3, I turn my attention to a few highly suggestive passages which I believe commentators have tended to neglect. These passages point to an alternative reading of Frege on which vague predicates do have a $B e-$ deutung (though not, perhaps, a concept). I do not claim that the view suggested by these passages represents Frege's considered view of the matter, but insofar as it represents at least one strand in his thinking, I maintain that these passages cast considerable doubt on the traditional reading. In the end, I conclude that we have good reason to resist ascribing SHARPNESS to Frege, and thus good reason to resist seeing him as committed to the suspect nihilism.

\section{Frege as Epistemicist?}

Nowhere does Frege clearly indicate how prevalent he considers unsharp predicates to be in everyday communication. He does admit to Peano that they are used "thousands of times in the language of life" (KS 236/NS 2:183/PMC 115), but this does not exactly settle the issue. Perhaps these thousands of occurrences are just a drop in the bucket. Could it be that on Frege's view, many of the predicates we use in ordinary speech actually succeed in denoting sharp concepts, even though our inadequate grasp of their senses leads us to think otherwise? In short, might Frege favor an epistemic approach to vagueness? Let us see. ${ }^{6}$

In an interesting discussion of the same puzzle that concerns us, Burge reads Frege along precisely these lines. He argues that on Frege's view, many of the predicates of conventional mathematics and perhaps also of ordinary discourse do in fact have fully determinate senses in virtue of which they denote sharp concepts. But these expressions often strike us as vague or at least incompletely defined because we fail to achieve a sharp grasp of their senses and therefore their Bedeutungen. In support of his reading, Burge calls attention to several texts in which Frege indicates that

\footnotetext{
${ }^{6}$ van Heijenoort also reads Frege as endorsing an epistemic approach to vagueness. However, he bases his interpretation on an apparent misreading of a passage from Section 26 of the Grundlagen der Arithmetik (FA 26). In this passage, Frege claims that in ordinary speech, color words like 'white' signify [bezeichnen] an objective quality rather than a subjective sensation. van Heijenoort takes this to mean that behind every vague predicate Frege postulates a sharply-defined objective property $(1986,37)$. But this misses Frege's meaning. When he remarks that 'white' signifies an objective quality, his point is just that we ordinarily conceive of white as a quality that objects possess independently of the activity of minds. In no way does he imply that these mind-independent qualities are sharply delimited.
} 


\section{FREGE ON VAGUENESS AND ORDINARY LANGUAGE}

our grasp of a sense or concept can sometimes fall short. Here is one such example, from the Preface to the Grundlagen der Arithmetik:

What is known as the history of concepts is really a history either of our knowledge of concepts or of the meanings of words. Often it is only after immense intellectual effort, which may have continued over centuries, that humanity at last succeeds in achieving knowledge of a concept in its pure form, in stripping off the irrelevant accretions which veil it from the eyes of the mind. (FA vii)

Here Frege admits that we often fail to grasp a concept in its pure form, and that only considerable effort can remove the veil that obscures the concept from us. The implication is not that we often fail to grasp a concept at all, but rather that until the veil is removed, our grasp of the concept is limited and imperfect.

There are other passages in which Frege acknowledges that our grasp of an expression's sense can fall short. This stands to reason. On his view, we always grasp an expression's Bedeutung through its sense, the mode of presentation of that Bedeutung. So if our grasp of a concept falls short, it must be due to an inadequate grasp of the sense that fixes this concept as the Bedeutung of a predicate. The best example of such a passage comes from the 1914 essay Logic in Mathematics, in the context of a discussion of the wildly divergent definitions of number offered by various mathematicians. Frege notes that though mathematicians disagree about the nature of number, they still manage to express the same thoughts when they assert arithmetical sentences. He then offers an explanation of how this could happen:

Could it be that [...] this one associates basically the same sense with the word 'number' as that one, only he does not succeed in grasping this sense correctly? Perhaps the sense appears so hazy to them, as if through a fog [so nebelhaft verschwommen], that when they reach for it, they miss it. This one grasps perhaps to the right, that one to the left; and so they do not grasp the same thing, even though they intended to grasp the same thing. How thick must the fog [der Nebel] be to make this possible! (NS 1:234/PW 216-17)

In the previous text, Frege talked about a veil that separates us from concepts in their pure form. Similarly, in this passage he talks about a fog 


\section{FREGE ON VAGUENESS AND ORDINARY LANGUAGE}

or haze [Nebel] that prevents mathematicians from properly grasping the sense of the predicate 'number'. Later in the discussion he adds that one of these mathematicians, Weierstrass, manages to express the same thoughts about number as his fellow mathematicians because he has an "inkling" [Ahnung] of its nature, though the haziness [Unklarheit] of this inkling prevents him from articulating a correct definition (NS 1:239/PW 221).

These passages clearly show that on Frege's view, we sometimes fail to grasp the sense and Bedeutung of a predicate. They open the door to the thought that ordinary empirical predicates only seem to be vague or otherwise incompletely defined because we lack an adequate grasp of their senses. However, in none of them does Frege actually say or even imply that the sharpness of a predicate's sense and Bedeutung is part of what we can fail to grasp.

The strongest evidence for Burge's position comes from the 1891 essay On the Law of Inertia, in which Frege discusses Ludwig Lange's Historical Development of the Concept of Motion and its Prospective End Result (1886). In a passage reminiscent of the one quoted above from the Preface to the Grundlagen, Frege takes Lange to task for suggesting that a concept like that of motion could have a historical development:
A logical concept does not develop and it does not have a his- tory, at least not in the currently fashionable sense. Unlike the author, I see no great need for being able to talk about the his- tory of the development of a concept, and I find that there is good reason to avoid this phrase. If we said instead "history of attempts to grasp a concept" or "history of the grasp of the concept", this would seem to me much more to the point; for a [logical?] concept is something objective: we do not form it, nor does it form itself in us, but we seek to grasp it, and in the end we hope to have grasped it, though we may mistakenly have been looking for something where there was nothing. (KS 122/CP 133)

What makes this text particularly significant for our purposes is the way in which Frege goes on to illustrate the point that our grasp of a concept can be deficient. In the work being criticized, Lange opines that what drives us to develop a concept is the presence of contradictions within it. But one of the problems with this claim, according to Frege, is that it does not accurately describe what has happened in the case of motion. The development of this concept, or rather our understanding of it, was driven not by the presence of contradictions but by our ignorance of a sharp boundary. The 


\section{FREGE ON VAGUENESS AND ORDINARY LANGUAGE}

boundary between motion and non-motion appeared to be blurred. But since a genuine concept requires a sharp boundary, it became necessary to search for a sharp boundary behind the appearance of a blurred one (KS 123/CP 134).

Frege goes on to admit that no such boundary has ever been discovered for the concept of motion. But what matters most for our purposes is that on his view, a concept can appear to be unsharp when in reality it has a sharp boundary. Otherwise the appearance of a blurred boundary would not be a reason to search for a sharp boundary but rather a reason to conclude that there is no such concept.

Here, then, we have the clearest evidence yet for Burge's interpretation. Frege claims not only that our grasp of a concept can be better or worse, but also that we often fail to grasp a concept fully by perceiving it as unsharp when in reality it has a sharp boundary. This opens the door to saying that the predicates we employ in ordinary discourse actually manage to denote sharp concepts even though they seem to be vague or incompletely defined.

On the other hand, there are good reasons for doubting whether this is really Frege's view. For one thing, the texts discussed above underdetermine this result. What they do succeed in establishing is that on Frege's view, some concepts, such as the concept of motion, can be sharp even though they appear unsharp. However, nowhere does Frege say that he means for this account to apply to concepts in general, and nowhere does he claim that it applies to ordinary empirical predicates such as 'bald', 'tall', 'red', and so forth. Based on what he says in his discussion of the concept of motion, it would appear that he means for the account to apply to all logical concepts. But again, nowhere does he indicate that there are logical concepts corresponding to most or all of the predicates of ordinary discourse. Burge himself admits that Frege applies the model only to terms that play a role in the scientific enterprise, and that the model seems to apply less plausibly to other terms $(1991,51)$.

Other texts also seem to weigh against this sort of reading. In the first place, Frege explicitly affirms that predicates such as 'heap' fail to denote a sharp or determinate concept: "The fallacy known by the name 'Acervus' rests on this, that words like 'heap' are treated as if they designated a sharply delimited concept whereas this is not the case" (KS 236/NS 2:183/PMC 114; cf. BS 27; NS 1:168/PW 155). But most predicates of ordinary language seem to be vague in precisely the same way as 'heap'. It's hard to see how he could avoid concluding that 'bald', 'tall', 'small', 'heavy', 'hard', 'delicious', and thousands of other ordinary language pred- 


\section{FREGE ON VAGUENESS AND ORDINARY LANGUAGE}

icates are equally unsharp. Further, recall that in the letter to Peano he admits unsharp concept-words are used "thousands of times in the language of life" (KS 236/NS 2:183/PMC 115). As I noted above, this is not exactly an unequivocal endorsement of UBIQUITY, but the import of this admission would appear to be that unsharp predicates are at least prevalent in ordinary speech.

Another text that counts against reading Frege as an epistemicist comes from his discussion of the concept of motion in On the Law of Inertia, the same discussion that provides us with the best evidence for that sort of reading. Admittedly, this discussion clarifies that on Frege's view, what seems to be an unsharp concept can turn out to be a sharp concept after all. But in the case of motion, he admits, this does not seem to be the case. We have put a great deal of effort into finding a sharp boundary between motion and non-motion, and thus far no such boundary has been found. Had Frege been an epistemicist about vagueness, we might have expected him to draw the conclusion that the boundary of this concept is either unknowable or at least difficult to know. But that is not the conclusion he draws. Rather, he says that we are now perhaps in a position to conclude that our search for a sharp boundary has been unfruitful precisely because there is no such boundary to be found. In effect, he is suggesting, we are in a position to conclude that there probably is no logical concept of motion. Instead, what we have discovered is another sharp boundary in the same vicinity, namely, that between inertial rest and non-inertial rest. Frege's thought is therefore that if our attempts to find a sharp boundary for a putative concept repeatedly fail, we are entitled to conclude that there is no such boundary and therefore no such logical concept. Yet if we cannot find a sharp boundary for motion, then a fortiori we will be unable to find sharp boundaries for the concepts putatively denoted by 'bald', 'heap', and other ordinary empirical predicates. The clear implication would be that these predicates are all unsharp.

Finally, the frequency and urgency of Frege's warnings about the dangers of admitting unsharp predicates into logical discourse cast serious doubt on the epistemicist reading of Frege. Were it his view that all or even most ordinary predicates are sharp, then this danger would have been a largely illusory one. Most if not all predicates would already satisfy the sharpness requirement, and the requirement itself would become more or less trivial. Yet Frege appears to consider violations of this requirement to be a very live possibility. It is hard to see why he would have been so concerned to emphasize his sharpness requirement unless he thought many predicates genuinely failed to denote sharp concepts. 


\section{FREGE ON VAGUENESS AND ORDINARY LANGUAGE}

In light of these points, I consider it doubtful that Frege meant to advocate an epistemic approach to the vague empirical predicates that we employ in everyday life. Burge may indeed be right that he favored such an approach for the abstract terms that figure into the exact sciences, but we have little reason to think that he meant to extend this approach to vague or otherwise incompletely defined terms in general. The prospects for rescuing Frege from an unappealing nihilism by denying that he meant to endorse UBIQUITY thus seem rather dim.

\section{Vagueness from the Logical Point of View}

Given that there appears to be no room for doubting that Frege endorses TRUTH-VALUE and COMPOSITION, the only remaining possibility open to the interpreter is to query his commitment to SHARPNESS, the doctrine that unsharp predicates have no Bedeutungen. To my knowledge, no commentator has ever questioned his commitment to this doctrine, but in this section and the next, that is precisely what I will do.

Proponents of the traditional view cite a number of texts in support of their reading. In most of these Frege asserts one or more of the following roughly equivalent theses:

1. Logic cannot recognize unsharp concepts (KS 122/CP 133, NS 2:18283/PMC 114, NS 1:168/PW 155, NS 1:195/PW 180, GG 56-58/B 25962, GG 64/B 266).

2. A logical concept must be sharp (KS 123/CP 134).

3. From the point of view of logic, concepts must be sharp (FA 74, KS 236/NS 2:183/PMC 115).

4. It is impossible to set up logical laws concerning unsharp concepts (KS 135/CP 148/B 141, KS 236/NS 2:183/PMC 114, GG 56/B 259, GG 62/B 265).

These include most of the texts that Burge has in mind when he says that Frege's claims to the effect that vague expressions lack a Bedeutung are "frequent, straightforward and explicit" $(1991,37)$. But do they really establish Frege's acceptance of SHARPNESS? Taken at face value, it is far from clear that they do. Notice that every one of them contains an important qualification. What Frege claims is that unsharp concepts cannot be considered 


\section{FREGE ON VAGUENESS AND ORDINARY LANGUAGE}

logical concepts or be recognized by logic. They make logical laws impossible, and therefore cannot be allowed from the logical point of view. None of these claims commit him in any direct or obvious way to the thesis that vague predicates lack a Bedeutung, and in none of these texts does he actually state the thesis.

Consider a typical passage in which Frege affirms thesis (1), this one from On the Law of Inertia:

[The word 'concept'] is best assigned to logic; for logic would seem to have the oldest claim to it, and logic needs such an expression to be able to express its laws; and what is required of a concept for this purpose is a sharp boundary [....] If something fails to display a sharp boundary, it cannot be recognized in logic as a concept, just as something that is not extensionless cannot be recognized in geometry as a point, because otherwise it would be impossible to set up geometrical axioms. (KS 122/CP 133)

Burge directs his readers to this text in a parenthetical reference following his claim that on Frege's view "vague expressions lack a Bedeutung." He then offers the following commentary: "Frege states this principle repeatedly. We need not discuss his reasons" $(1991,32)$. Notice, however, that Frege affirms no such principle in this passage. What he says is that logic can only recognize as concepts things that have sharp boundaries, since otherwise it would not be able to express its laws. But it manifestly does not follow from this that unsharp predicates must lack a Bedeutung, unless we assume it to be a necessary condition on the Bedeutung of a predicate that it be something logic can recognize as a concept. Perhaps Burge is assuming this, and that is why he sees this text as evidence for his interpretation. But nothing Frege says licenses such an assumption. To the contrary, it is consistent with everything he says to suppose that predicates can have a Bedeutung that logic could not recognize as a concept. I will spare the reader the details, but essentially the same point can be made in all the other cases in which Frege affirms theses (1)-(4).

Of all these passages perhaps the one that comes closest to supporting the traditional reading comes from an 1896 letter to Peano. The relevant remarks appear in the context of a critique of conditional definitions. Frege's fundamental objection to such definitions is that they lead to failures of logical laws. A conditional definition of a word such as 'prime' defines that predicate only for a certain range of objects, such as the natural numbers. Hence, some objects will be neither prime nor not prime, in violation of 


\section{FREGE ON VAGUENESS AND ORDINARY LANGUAGE}

the law of excluded middle. ${ }^{7}$ This leads him, in the course of his critique, to call attention to his sharpness requirement on concepts: "logic can only recognize sharply delimited concepts. Only under this presupposition can it set up precise laws" (NS 2:182-83/PMC 114). Just three sentences later he reiterates the requirement:

Just as it would be impossible for geometry to set up precise laws if it tried to recognize threads as lines and knots in threads as points, so logic must demand sharp limits of what it will recognize as a concept unless it wants to renounce all precision and certainty. Thus a sign for a concept the content of which does not satisfy this requirement is to be regarded as bedeutungslos from the logical point of view. (KS 236/NS 2:183/PMC 114-15; cf. NS 1:195/PW 180)

Once again we find no evidence in these statements for ascribing SHARPNESS to Frege. ${ }^{8}$ He does say that unsharp concept-words lack a Bedeutung from the logical point of view, but the whole point of the qualification seems to be to leave open the possibility that there is some other point of view from which such terms do have Bedeutung. The thought is not that an unsharp predicate is bedeutungslos tout court. If anything, Frege implies that such predicates do have Bedeutungen whose content fails to satisfy the sharpness requirement. The thought is rather that for the purposes of logic, an unsharp concept-sign is as good as bedeutungslos, and therefore should be regarded as such, even though it may not in fact be bedeutungslos.

Apart from the texts in which Frege affirms some version of (1)-(4), the passage that provides by far the best evidence of his acceptance of SHARPNESS is the remark from Comments on Sense and Bedeutung quoted at the outset of this essay. Here is the passage in context:

If it is a question of the truth of something - and truth is the goal of logic - we also have to inquire after Bedeutungen; [...] [W]e

\footnotetext{
${ }^{7}$ NS 1:168/PW 155; NS 1:193-95/PW 179-80; KS 236/NS 2:183/PMC 114; GG 56/B 259. Indirect proofs would fail as well: see NS 1:195/PW 180.

${ }^{8}$ Frege also claims, just a few lines above the quoted passage, that conditional definitions fail to assign a Bedeutung to a sign. Taken at face value, this claim admittedly supports the traditional reading. However, if we bear in mind Frege's justification for it- that such definitions fail to determine a sharp concept, and "logic can only recognize sharply delimited concepts" (NS 2:182-83/PMC 114)—then another possibility suggests itself. Frege's point may be not that a conditional definition fails to assign a Bedeutung tout court, but that it fails to assign anything that could be recognized as a Bedeutung by logic.
} 


\section{FREGE ON VAGUENESS AND ORDINARY LANGUAGE}

have to throw aside concept-words that do not have a Bedeutung. They are $[\ldots]$ such as have vague boundaries. It must be determinate for every object whether it falls under a concept or not; a concept word which does not meet this requirement on its Bedeutung is bedeutungslos. (NS 1:133/PW 122)

Here Frege seems to be claiming in no uncertain terms that unsharp predicates fail to have a Bedeutung. A closer look, however, suggests that the passage may not be so straightforward. Notice that this passage begins with a conditional: If we are concerned with truth (i.e., logic), then we must inquire after Bedeutungen and cast aside both proper names and predicates that fail to have a Bedeutung. He then immediately clarifies that it is vague predicates in particular that are bedeutungslos. One possibility to which we should be open is that what Frege says in the last two sentences quoted above is only an extension of the consequent of the conditional and that he means for it to be governed by the conditional's antecedent. That is, his point might be not simply that unsharp predicates are bedeutungslos, but that they are or must be regarded as bedeutungslos from the logical point of view, that is, when we are concerned with truth or logic. It is also worth remembering that in the letter to Peano, written around the same time, ${ }^{9}$ we find a nearly identical statement: "[A] sign for a concept whose content does not satisfy this [sharpness] requirement is to be regarded as bedeutungslos from the logical point of view" (KS 236/NS 2:183/PMC 115). Here Frege has taken care to include a critical qualification, restricting himself to the logical point of view. Could it be that this is also what he was thinking when he penned the Comments passage and that he simply neglected to add the qualification that he remembered to include in the letter to Peano? I suspect so.

To summarize: Most of the texts usually cited in support of ascribing SHARPNESS to Frege support that ascription only in conjunction with certain assumptions which we have little reason to impute to him, and even those passages which provide the strongest support for the traditional reading are far from unequivocal. In light of these points, I conclude that the textual case for attributing SHARPNESS to Frege is not particularly strong. At the very least it is much weaker than proponents of the traditional view have been willing to admit.

My reading of the texts discussed in this section relies heavily on the idea that Frege distinguishes between the logical point of view and one or

\footnotetext{
${ }^{9}$ Frege composed Comments between 1891 and 1895. The letter to Peano is dated 29 September 1896.
} 


\section{FREGE ON VAGUENESS AND ORDINARY LANGUAGE}

more non-logical points of view (about which I will have more to say in the next section). My proposal is that when Frege suggests that unsharp predicates have no Bedeutung (SHARPNESS), his point, properly speaking, may be simply that these predicates have no Bedeutung from the point of view of logic. If that is the case, then these texts leave the door open to the possibility that there is another, non-logical point of view on which unsharp predicates do have some sort of Bedeutung. Yet, it has been suggested by Kemp that Frege's statements about the nature of logic leave no room for any such distinction between logical and non-logical points of view. In his discussion of the sharpness requirement, Kemp places great emphasis on Frege's commitment to the universality of logic, the idea that the laws of logic (thought, truth) pertain to "everything that can be thought" and accordingly express not just how things ought to be, but how they actually stand. "It is, simply, one of the laws of truth," says Kemp, "that $(\forall x)(\forall F)(F x \vee \neg F x)$ - that for any concept and any object, either the object falls under the concept, or it falls under its contradictory" $(1996,172)$. Hence, on Frege's understanding of such laws, "logical formulae such as that asserting the law of excluded middle acquire a thoroughgoing factual portentousness; they assert that reality is really like that." In view of this, Kemp concludes, it is "misleading to speak of what logic can and cannot 'recognize'; it has already been defined as recognizing everything" (ibid., 173). The logical point of view, that is, is the only point of view, and so predicates that lack a Bedeutung from this point of view must be altogether bedeutungslos. ${ }^{10}$

I want to concede much of what Kemp says about Frege's conception of logic as universal. In particular, I share with him the view that Fregean laws of logic are the most general laws. They apply not just to particular types of objects (e.g., physical objects) or concepts (e.g., psychological concepts), but to objects and concepts in general. Kemp is quite right that the law of excluded middle, as understood by Frege, asserts that for any object and any concept, the object determinately falls under either that concept or its contradictory. Such laws do indeed assert that reality is really like that. However, to admit this much is in no way to commit oneself to the conclusion that for Frege, logic recognizes everything. To my knowledge, Frege never claims that objects and concepts exhaust the furniture of the universe. Nor does he ever claim that concepts are the only entities with a predicative nature. As I read him, he claims only that objects and concepts

\footnotetext{
${ }^{10}$ For more on Frege's universalist conception of logic, see Goldfarb 2010, especially 6771.
} 


\section{FREGE ON VAGUENESS AND ORDINARY LANGUAGE}

exhaust the logical furniture of the universe. As far as logic is concerned, the only entities that can be recognized are objects and concepts, and the laws of logic are the most general laws about these entities. They embrace all objects and concepts, all of the logical furniture of the universe. In this sense, logic is indeed universal. But it does not follow that logic is universal in the sense that embraces absolutely everything. Very little that Frege says is inconsistent with conceiving of logic as universal in that sense, but nothing he says commits him to that conception either. ${ }^{11}$ I therefore find little reason to follow Kemp in dismissing Frege's talk of the logical point of view in contrast with other, non-logical points of view, such as that of ordinary speech.

All told, the evidence given by proponents of the traditional view in support of their claim that Frege endorsed SHARPNESS is rather weak. In only one of the passages does Frege actually affirm the thesis, and in light of what he says elsewhere it is quite plausible to conclude that in so doing he inadvertently misrepresents his considered view.

\section{Vagueness in Ordinary Speech}

Upon closer inspection, the evidence usually offered in support of imputing SHARPNESS to Frege turns out to be surprisingly weak. But as I will argue in this section, there are also texts in Frege's writings which count against the traditional reading. Though they are far from conclusive, they do suggest that at least in some moods he thought unsharp predicates could have a kind of Bedeutung. I will discuss the three most suggestive of these passages.

The first and most telling passage comes from the letter to Peano discussed above. In the context of his critique of conditional definitions, as we have seen, he asserts that unsharp predicates must be regarded as bedeutungslos from the logical point of view. He then entertains the objection that such words are nevertheless used "thousands of times in the language of life," to which he replies:

Yes, but our vernacular languages [Volkssprachen] are also not made for conducting proofs. [....] The task of our vernacular languages is essentially fulfilled if people engaged in com-

\footnotetext{
${ }^{11} \mathrm{Cf}$. Frege's remark that sentences which fail to express a thought or which express a thought belonging to myth or fiction "fall outside the domain governed by logic" (NS $1: 195 /$ PW 180). The clear implication is that the domain governed by logic is not absolutely unrestricted.
} 


\section{FREGE ON VAGUENESS AND ORDINARY LANGUAGE}

munication with one another connect the same thought, or approximately the same thought, with the same sentence. For this it is not at all necessary that the individual words should have a sense and Bedeutung of their own [für sich], provided only that the whole sentence has a sense. Where inferences are to be drawn the case is different: for this it is essential that the same expression should occur in two sentences and should have exactly the same Bedeutung in both cases. It must therefore have a Bedeutung of its own [für sich], which is independent [unabhängig] of the other parts of the sentences. In the case of incompletely defined concept-words there is no such independence [Unabhängigkeit]; rather, what matters in such a case is whether the case at hand is one to which the definition refers, and that depends on the other parts of the sentences. Such words cannot therefore be acknowledged to have an independent [selbständige] Bedeutung at all. This is why I reject conditional definitions of concept-signs. (KS 236/NS 2:183/PMC 115; cf. GG 66/B 269)

I think it would be fair to say that in this passage, Frege is contrasting the logical point of view, to which he has just alluded, with another, non-logical point of view. From the logical point of view, truth is the goal and a language free of logical defects is essential. Each expression of the language, each proper name and predicate, must have an independent Bedeutung or Bedeutung of its own. That is, expressions in the language must not only have a Bedeutung in every sentence in which it they occur; they must have the very same Bedeutung in each occurrence. (This is really just the sharpness requirement in another guise.) Only in that case will the language be such as to uphold the laws of logic. From the other, vernacular point of view, however, it is not at all necessary that expressions have an independent Bedeutung. Here, Frege claims, the goal is not so much truth as it is the communication of thoughts, and for this purpose it is not at all necessary that an expression have a Bedeutung or even a sense of its own. What matters is only that the sentence itself has a sense.

From the fact that an expression does not have a Bedeutung of its own, Frege does not infer that it has no Bedeutung at all. Rather, his thought appears to be that an expression can acquire a Bedeutung in a particular context. In the case of an incompletely defined predicate, what matters is "whether the case at hand is one to which the definition refers" (ibid.). Thus, if the predicate 'prime' is defined only for the natural numbers, then 


\section{FREGE ON VAGUENESS AND ORDINARY LANGUAGE}

in the sentence 'The moon is prime', the predicate would be bedeutungslos. But in the sentence ' 7 is prime', the thought would seem to go, 'prime' would acquire a Bedeutung. Likewise, if Fred happens to be a borderline case of baldness, then in the sentence 'Fred is bald' the predicate will fail to have a Bedeutung. But if Fred happens to be either determinately bald or determinately not bald, then 'bald' will acquire a Bedeutung in the sentence 'Fred is bald'. In this way, a predicate that does not have a Bedeutung of its own can nevertheless acquire a (dependent) Bedeutung in the right sorts of contexts.

Frege does not say whether a sentence in which the predicate acquires a Bedeutung itself has a Bedeutung, that is, a truth-value. But if the complete expressions entering into the sentence all denote objects, and the predicate has a Bedeutung at least in the context of that sentence, then it would seem to follow on Fregean principles that the sentence itself also has a Bedeutung. His thought would appear to be that if the rest of the sentence specifies a context in which an incompletely defined predicate happens to be defined, then the predicate will acquire a Bedeutung; and the object denoted by the proper name of the sentence with either fall under or fail to fall under this Bedeutung. In the former case, the sentence will be true, and in the latter, false.

One further point before moving on. Some readers of this passage have understood Frege to be suggesting that ordinary language sentences typically have a sense (i.e., express a thought) even though not all of their component expressions have a sense, a view which involves treating vague sentences, implausibly enough, as idioms (Williamson 1994, 44-45; van Heijenoort 1986, 38-39). But it is far from clear that this is what Frege intended to suggest. Nowhere in the passage does he actually say that a sentence can have a sense even though it contains a senseless expression. What he says is that a sentence can have a sense even though its constituents do not have a sense of their own. He may well be thinking that just as a predicate without a Bedeutung of its own can acquire a (dependent) Bedeutung in a particular context, a predicate without a sense of its own can acquire a (dependent) sense in a particular context. We need not suppose that he is thinking of vague sentences as idioms.

Another passage along similar lines can be found in The Argument for My Stricter Canons of Definition, written a year or two after the letter to Peano. In this essay, Frege once again argues for the importance of his sharpness requirement on concepts. One of his arguments is that the law of excluded middle requires that every concept have sharp boundaries. Another is that correct inference requires that predicates have an independent 


\section{FREGE ON VAGUENESS AND ORDINARY LANGUAGE}

\section{Bedeutung:}

Inference from two premises very often, if not always, depends on a concept being common to both of them. If a fallacy is to be avoided, not only must the concept-sign be the same, it must also mean [bedeuten] the same. It must have a Bedeutung independent of the context [unabhängig vom Zusammenhange] and not first come to acquire one in context [Zusammenhange], which is no doubt what very often happens with the words of speech. (NS 1:168/PW 155)

Here Frege makes explicit an aspect of his view that was only implicit in the letter to Peano. He says that in ordinary speech predicates that lack an independent Bedeutung often acquire a Bedeutung in context, that is, in the context of a particular sentence. Read in conjunction with the Peano passage, Frege's meaning is clear. An unsharp predicate does not have a Bedeutung of its own, but can nevertheless acquire a Bedeutung in a particular context if the predicate happens to be defined for the relevant objects (as determined by the context).

It might seem that in this passage Frege has in mind the phenomenon of ambiguity, not unsharpness. From this point of view, his point is just that logic requires us to eliminate ambiguity because otherwise the same predicate can have different meanings in different premises, thus rendering the inference fallacious. However, the broader context makes it clear that the issue here is not ambiguity. The text appears in the midst of a discussion of the sharpness requirement, and Frege introduces the text by saying that he is going to provide another reason for insisting on that requirement. But why would the threat of fallacy due to ambiguity be a reason for insisting on sharp concepts? The problem of predicates that denote different concepts in different contexts and that of predicates or concepts that are not defined for all objects are different problems, and Frege does not conflate them. When he warns that a concept-sign must have the same Bedeutung in every premise in which it occurs, just as he had warned in his discussion of the sharpness requirement in the letter to Peano (KS 236/NS 2:183/PMC $115)$, what he has in mind is not the case where the predicate denotes different concepts in different premises (i.e., ambiguity), but rather the case where a predicate lacking an independent Bedeutung acquires a Bedeutung in one premise but not the other. In such a case, the signs are the same but they do not mean (bedeuten) the same, and that can lead to fallacy.

The final passage I will consider comes from the second volume of the Grundgesetze der Arithmetik. Frege opens Part III of the Grundgesetze with a 


\section{FREGE ON VAGUENESS AND ORDINARY LANGUAGE}

discussion of concepts in which we find some further hints about the $\mathrm{Be}$ deutungen that unsharp predicates acquire in certain contexts. Toward the beginning of this discussion, Frege insists that, properly speaking, unsharp concepts do not exist, that the very idea of an unsharp concept is incoherent. In $\S 56$, he likens concepts to areas on a plane:

To a concept without sharp boundary there would correspond an area that had not a sharp boundary-line all round, but in places just vaguely faded away into the background. This would not really be an area at all; and likewise a concept that is not sharply defined is wrongly termed a concept. (GG 56/B 259)

In $\S 62$, he calls these things "inadmissible pseudo-concepts" [unzulässige Scheinbegriffe] and again denies that they are genuine concepts (GG 62/B 264). Given that Frege seems to use the word 'concept' to refer to the Bedeutung of a predicate, we might be tempted to infer from these remarks that he does not think unsharp predicates can have a Bedeutung. But this is not his position. He does not infer from the non-existence of unsharp concepts that incompletely defined predicates lack a Bedeutung; rather, he infers that their Bedeutungen are not, properly speaking, concepts. He characterizes them instead as "concept-like constructions" [begriffsähnliche Bildungen] which logic cannot recognize as concepts, things that are "still fluid and have not yet been given definitive and sharp boundaries" (GG 58/B 261-62). These constructions are presumably concept-like in the sense that they have a predicative nature. But unlike concepts, they have not yet been given sharp boundaries. They are, I submit, the same Bedeutungen Frege elsewhere says unsharp predicates can come to acquire in particular contexts.

Taken together, the texts I have been considering in this section suggest the following view. In addition to objects and concepts, there is a class of predicative entities that are like concepts but are not sharply delimited. These concept-like constructions are the Bedeutungen of vague or otherwise incompletely defined predicates. Such predicates do not have a Bedeutung of their own, but can come to acquire a Bedeutung in a particular context if that context happens to be one for which the construction has been defined. If the context is one for which the construction has been defined, then the predicate acquires that construction as a Bedeutung and the sentence in turn acquires a truth-value. But if the context is not one for which the construction has been defined, then the predicate does not acquire a Bedeutung and so the sentence is neither true nor false, even though it might express a 


\section{FREGE ON VAGUENESS AND ORDINARY LANGUAGE}

thought. This, in short, is the view Frege appears to be advocating in these texts.

In Section 2, I argued that the evidence for ascribing SHARPNESS to Frege is inconclusive at best. This alone gives us good reason to doubt whether Frege really intended to endorse that doctrine. But to this we can now add another reason. As I have argued in this section, there is unmistakable evidence that at least in some moods, Frege believed that vague predicates can acquire a Bedeutung within the context of a particular sentence. So not only is the evidence for ascribing SHARPNESS to him wanting, there is good evidence that he meant to reject that doctrine. Of course, the latter evidence is admittedly somewhat thin. To my knowledge, it consists of only the three passages discussed above. For that reason, I hesitate to claim that this approach to vagueness represents anything like Frege's considered view of the matter. Still, it does furnish us with an additional reason to doubt whether Frege really believed SHARPNESS, and thus, whether he in fact committed himself to a nihilist approach to vagueness. All things considered, I think it would be reasonable to conclude that he does not clearly commit himself to any such nihilism.

\section{Concluding Remarks}

Having completed the interpretive component of my argument, I want to conclude with a few reflections on the philosophical merits and possible demerits of the theory of vagueness Frege advocates in the texts just discussed.

On the plus side, the theory seems to get things right in at least one important respect. In the contexts where no borderline or undefined case is in view, the theory says, vague predicates acquire a Bedeutung. This presumably means that in such contexts the sentence itself also has a Bedeutung. So in cases where the predicate is defined for the object or objects in question, the sentence has a truth-value. This is just as we would expect. If Fred is either clearly bald or clearly hirsute, then we would expect the claim that Fred is bald to have a determinate truth-value. In contrast, if the sentence does pertain to a borderline or undefined case, then Frege's theory says that the predicate does not acquire a Bedeutung, and given COMPOSITION and TRUTH-VALUE, it follows that the sentence is neither true nor false. This too is just as we would expect. If Fred is a borderline case of a bald man, it stands to reason that the sentence 'Fred is bald' lacks a truth-value. In these respects, the theory falls very much in line with our ordinary ways 


\section{FREGE ON VAGUENESS AND ORDINARY LANGUAGE}

of thinking about sentences containing vague or otherwise incompletely defined expressions.

On the down side, the theory raises several difficulties for Frege. First, though the view works well in the case of unquantified sentences such as 'Fred is bald', it is unclear whether it can handle quantified sentences such as 'Some men are bald' and 'All dunes are heaps'.12 In order to get the desired result in these cases, Frege would have to hold that whether the vague predicate acquires a Bedeutung or not depends not simply on whether the corresponding concept is defined for the Bedeutung of an adjoining proper name, but on a more complex set of facts. For instance, in the sentence 'Some men are bald', he would have to say that 'bald' acquires a Bedeutung just in case the concept bald is either defined for all men, in which case the sentence will be either true or false, or defined for some man who falls under that concept, in which case the sentence will be true. Similarly, he would have to say that 'heap' acquires a Bedeutung in the context of the sentence 'All dunes are heaps' just in case the concept heap is either defined for all dunes, in which case again the sentence will be either true or false, or defined for some dune which fails to fall under that concept, in which case the sentence will be false. In short, whether a vague predicate acquires a concept as Bedeutung in the context of a quantified sentence would depend not just on whether that concept is defined for a single object denoted by an adjoining proper name, but on whether that concept is defined for either all objects in the relevant domain, as specified by the rest of the sentence, or at least one object that falls or fails to fall under that concept. Yet it is far from easy to see how a predicate's acquisition of a Bedeutung could be sensitive to such complex, disjunctive conditions.

Second, in the letter to Peano he suggests that unsharp predicates lack not only a Bedeutung of their own but a sense of their own. This implies that if a predicate acquires a Bedeutung in a particular context, it also acquires a sense, and that otherwise it acquires neither. So Frege's position would appear to be that if Fred is a borderline case of a bald man, then in the sentence 'Fred is bald' the predicate has neither sense nor Bedeutung. The problem with this is that if 'Fred is bald' has a sense or expresses a thought, then it would seem to do so in virtue of the senses of its parts. So if 'bald' lacks a sense in the context of this sentence, then the sentence itself would also lack a sense. This consequence would be entirely unproblematic if the sense of an expression were simply that which determines its reference. According to Frege, however, the sense of a sentence does more

\footnotetext{
${ }^{12}$ I owe this point to an anonymous referee.
} 


\section{FREGE ON VAGUENESS AND ORDINARY LANGUAGE}

than just fix its reference; it also makes an essential contribution to its informational content or "cognitive value" [Erkenntniswert] (PMC 165/B 291). Thus, in denying that 'bald' acquires a sense in borderline contexts, Frege seems to have committed himself to the implausible view that sentences such as 'Fred is bald' not only have no truth-value but do not even express a thought or communicate any information. Surely that is too strong.

One option available to Frege would be to claim that, on second thought, vague predicates do have or acquire a sense (though not a Bedeutung) even in contexts where a borderline case is in view. This would be tantamount to admitting that an expression can have a sense of its own but not a $B e-$ deutung of its own. The problem with this line of reply, however, is that the sense of an expression is supposed to determine its Bedeutung, if it has one at all. Frege does not require that a sense determine a Bedeutung. ${ }^{13}$ Fictional names, for example, have senses that fail to determine a Bedeutung. But if a sense does fix a Bedeutung at least in some contexts, then it should fix a Bedeutung in every context in which it appears. To put the point another way, if an expression has a context-independent sense, then it should also have a context-independent Bedeutung. Yet the theory was supposed to be that vague predicates do not have a Bedeutung independent of context. To defend the theory in this way would be tantamount to giving it up.

One way Frege could avoid this result would be to hold that the sense a vague predicate acquires in borderline contexts differs from the sense it acquires in non-borderline contexts. That is, if John is clearly bald and Fred is a borderline case of a bald person, Frege could claim that 'bald' has different senses in 'John is bald' and 'Fred is bald'. For one thing, the sense it acquires in the former context would determine a Bedeutung, whereas the sense it acquires in the latter context would not. This would allow Frege to hold that vague sentences have a truth-value if and only if no borderline case is in view. But it would also require him to take the implausible position that 'bald' makes a different contribution to the meaning of 'John is bald' (that is, the thought that sentence expresses) than it makes to the meaning of 'Fred is bald'.

The third and final concern raised by Frege's theory concerns the idea of a predicate acquiring a Bedeutung in the context of a particular sentence. This idea may strike us as puzzling. What is to be gained by saying that an unsharp predicate acquires a Bedeutung in certain contexts? Why not just hold that the predicate denotes that Bedeutung in all contexts? The result, it

\footnotetext{
${ }^{13}$ For more on this position and the problems it raises in the context of Frege's philosophy, see McDowell 1977; Dummett 1981, 129-138; Salmon 1990, 235-46; Williamson 1994, 45.
} 


\section{FREGE ON VAGUENESS AND ORDINARY LANGUAGE}

seems, would be the same. In the case of borderline contexts, the predicate would denote the same Bedeutung it denotes in every other context, but since that Bedeutung isn't defined for the object(s) in question, the sentence would have no truth-value, just as we would expect. If Frege is willing to admit that some predicative Bedeutungen lack sharp boundaries, then nothing seems to be gained by adding that no predicate can have this sort of Bedeutung independently of a context.

I would like to propose an explanation for Frege's belief that an unsharp predicate can have a Bedeutung only in certain contexts. My thought is that he may not want to allow an unsharp predicate to have an incompletely defined Bedeutung of its own because that would commit him to the implausible position that all vague sentences have truth-values, even in cases where a borderline case is in view. The reason it would do so, I speculate, is that on Frege's view, anytime the sign for an object is concatenated with the sign for a predicative entity, the object must in some sense complete or saturate the predicative entity. The two entities are like oppositely charged magnets which, when brought into close vicinity, can't help but cling to one another and form a third thing. But for an object to complete or saturate a predicative entity is just for the sentence resulting from the concatenation of the corresponding signs to have a Bedeutung, a truth-value. ${ }^{14}$ This may be part of what he has in mind when he characterizes the Bedeutungen of the parts of a sentence as in some sense parts of the Bedeutung of the whole (KS 150/CP 165/B 159). My conjecture, then, is that Frege may have wanted unsharp predicates to have a Bedeutung only in certain contexts because he wanted to avoid the unappealing result that vague sentences always have a truth-value.

\section{References}

BAKER, G. P., \& HACKer, P. M. S. 1984. Frege: Logical Excavations. New York: Oxford University Press.

Burge, Tyler. 1991. Frege on Sense and Linguistic Meaning. In: Bell, D., \& CoOper, N. (eds), The Analytic Tradition. B. Blackwell.

DummetT, Michael. 1974. Frege: Philosophy of Language. Cambridge: Harvard University Press.

\footnotetext{
${ }^{14}$ Cf. Introduction to Logic, NS 1:211/PW 194: "If a sentence can be split into parts, each of which is bedeutungsvoll, then the sentence also has a Bedeutung."
} 


\section{FREGE ON VAGUENESS AND ORDINARY LANGUAGE}

Dummett, Michael. 1981. The Interpretation of Frege's Philosophy. Cambridge: Harvard University Press.

Goldfarb, Warren. 2010. Frege's Conception of Logic. In: PotTer, Michael, \& RicketTs, TOM (eds), The Cambridge Companion to Frege. New York: Cambridge University Press, 63-85.

KEMP, GARY. 1996. Frege's Sharpness Requirement. Philosophical Quarterly, 46, 168-184.

MCDowell, John. 1977. On the Sense and Reference of a Proper Name. Mind, 86, 159-185.

REIN, ANDREW. 1985. Frege and Natural Language. Philosophy, 60, 513524.

SALMON, NATHAN. 1990. A Millian Heir Rejects the Wages of Sinn. In: ANDerson, C. Anthony, \& OWens, Joseph (eds), Propositional Attitudes: The Role of Context in Logic, Language, and Mind. Stanford: CSLI.

VAN HeijenOORT, JEAN. 1986. Frege and Vagueness. In: HaAPARANTA, L., \& HiNTIKKA, J. (eds), Frege Synthesized. D. Reidel.

WeIner, JOAN. 1990. Frege in Perspective. Ithaca: Cornell University Press.

Williamson, Timothy. 1994. Vagueness. New York: Routledge. 